\title{
Total quality management in the health-care context: integrating the literature and directing future research
}

This article was published in the following Dove Press journal:

Risk Management and Healthcare Policy

\author{
Majdi M Alzoubi \\ KS Hayati ${ }^{\prime}$ \\ AM Rosliza' \\ AA Ahmad' \\ ZM Al-Hamdan ${ }^{2}$
}

'Department of Community Health, Faculty of Medicine and Health Sciences, University Putra Malaysia, UPM Serdang, Selangor Darul Ehsan 43400, Malaysia; ${ }^{2}$ Department of Nursing Management, Faculty of Nursing, Jordan University of Science and Technology, Irbid, Jordan

Correspondence: KS Hayati

Department of Community Health, Faculty of Medicine and Health Sciences, University Putra Malaysia, UPM Serdang, Selangor Darul Ehsan 43400, Malaysia Email hayatik@upm.edu.my
Background: Synergistic integration of predictors and elements that determine the success of total quality management (TQM) implementations in hospitals has been the bane of theoretical development in the TQM research area. Thus, this paper aims to offer a systematic literature review to provide a foundation on which research on TQM can be built and to identify the predictors of successful TQM in the health-care context.

Materials and methods: A systematic literature survey was adopted in this paper, involving the review of 25 relevant researched articles found in the databases Science Direct, EBSCO, MEDLINE, CINAHL and PubMed.

Result: The systematic literature survey reveals five variables to be core predictors of TQM, signifying how important these variables are in the successful implementation of TQM in the health-care context. Also, it is revealed that the identified core predictors have positive effects on an improved health-care system. However, the systematic survey of the literature reveals a dearth of studies on TQM in the health-care context.

Conclusion: As TQM has become an important management approach for advancing effectiveness in the health-care sector, this kind of research is of value to researchers and managers. Stakeholders in the health sectors should introduce and implement TQM in hospitals and clinics. Nevertheless, this study has limitations, including that the databases and search engines adopted for the literature search are not exhaustive.

Keywords: total quality management, total quality management implementation, health care, commitment, systematic literature review, critical success factors

\section{Introduction}

Given the snowballing global economic competition and other external pressures, organizations have been compelled to pursue enduring quality and quality management which will, in turn, enhance their competitive advantage. Quality as a concept has metamorphosed over the years, and it involves objective quality bordering on the characteristics and quality of goods and services that meet implicit and explicit customer demands. It also includes subjective quality which denotes the capability to produce goods and services in the best, effective and efficient manner. ${ }^{1}$

Looking at the health-care context, quality has always been aimed at since the time of Florence Nightingale. ${ }^{2}$ Given that quality assurance is a requisite for economic survival, ${ }^{3}$ and that it is an ethical, legal and social rights matter, ${ }^{4}$ the health sector has been worried about it for more than a decade. ${ }^{2}$ Quality assurance is significant as it concerns customer satisfaction and the reduction of risks connected with health care to a minimum. ${ }^{5}$ In the present time, health care has become a developing profession with an approach to care quality via the appraisal and regulation of structure, process and care result components. ${ }^{6}$ 
Given the ever-increasing competitive and dynamic environment in which hospitals operate, and the need to augment hospitals' performance and health-care quality, researchers ${ }^{2,7-9}$ have conducted considerable research on enhancement of health-care quality. Moreover, given that nurse performance is crucial to the overall performance of the hospital and effective health-care system, there has been a research focus on nurse performance. ${ }^{7}$ Nurses represent a large percentage of the health workers in any hospital. Nurses would play a significant role in the implementation of any intervention programs introduced by any hospital.

Moreover, research ${ }^{8-11}$ has shown that the health-care system is facing a myriad of challenges which include high care cost, swiftly increasing dependence on technology, economic pressure on health organizations, reduction in healthcare quality, ${ }^{8,10}$ fulfillment of patients' needs, ${ }^{9}$ augmented numbers of patients who are suffering from multiple illnesses, increased demand for high-quality care, increased health-care costs and cost-containment pressures (Organization for Economic Cooperation and Development [OECD] 2007). ${ }^{11}$ Some studies have indicated that an active way of surmounting health-care challenges is through an intervention program that will border on quality management (eg, total quality management [TQM]). ${ }^{12}$

TQM is a system implemented by the management of an organization to achieve the satisfaction of customers/ patients. ${ }^{13}$ The importance of TQM as a strategy to improve organizational performance has grown in this era of globalization. ${ }^{14}$ Numerous research has revealed the role of TQM in the enrichment of system quality and enhancement of both employee and organizational performance. TQM is known for continuous quality improvement, quality management and total quality control. ${ }^{10}$ TQM is held to be an innovative approach to the management of organizations. In the medical sector, TQM integrates quality orientation in all processes and procedures in health-care delivery. ${ }^{15}$ It is now being widely adopted in the medical sector of many countries. The research by Vituri and Évora ${ }^{2}$ indicates that the literature on TQM in health sectors reveals that TQM has been fully adopted in some health institutions.

The implementation of TQM, upon which the success of TQM hinges, is intricate and complex; it depends on a good combination of certain predictors (ie, critical success factors $[\mathrm{CSF}]$ ), and its benefits are difficult to accomplish. ${ }^{16}$ Different means of integrating predictors of TQM, although inconsistent, have emerged in the literature. ${ }^{17}$ Some predictors have been considered crucial to TQM success, ${ }^{18}$ and thus the exceptional predictors which can be adopted by organizations, irrespective of their industry, type, size or location. ${ }^{19}$ These predictors are regarded as the determinants of firm performance via effective implementation of TQM.

Nevertheless, synergistic integration of predictors and elements, otherwise known as CSFs and which determine the success of TQM implementation, has been the bane of theoretical development in the TQM research area. Some of these predictors have been reported, by extant studies, ${ }^{20}$ to have a positive impact on performance.

Likewise, substantive problems exist and can hamper theoretical development in the research area. The literature lacks foundation and structure on which the research on TQM in the health-care context is based, and connections between studies on TQM in the health-care context can hardly be drawn. The current state of extant research on TQM in the health-care context indicates that there is a need for more research in the area. ${ }^{21}$ New knowledge development regarding identification of fitting predictors for successful TQM that enhance effectiveness in the health-care sector should be developed and where further research needs to be done should be identified.

Considering the extant works on a systematic literature review on predictors of TQM, two English written studies $^{14,22}$ are discernible, but Hietschold et $\mathrm{al}^{14}$ focused on CSFs of TQM in general contexts while Aquilani et $\mathrm{al}^{22}$ focused on the identification of TQM research, implementation of TQM research and impact-of-TQM-on-performance research in general contexts. Besides these two studies, no studies have focused on the systematic literature survey of predictors/elements of TQM in the healthcare context.

Therefore, undertaking a systematic literature review in this aspect of research is germane, and this paper is poised to do as such. This paper conducts a systematic literature survey to provide a foundation stone on which research on TQM in the health-care context can be built, to evaluate the current state of evidence for TQM in the health-care context, to reveal inadequacies in the literature and to point to where further research needs to be done.

\section{Methods}

This research is guided by the following research question: what are the predictors of successful TQM in the healthcare context between the period of 2005 and 2016? Like the two previous studies on a systematic literature review 
of TQM, this paper adopts and applies the three core steps of planning, execution and reporting that constitute a systematic literature survey. ${ }^{23}$

This research seeks to obtain the most important predictors of successful TQM in the health-care context. This includes the review of published peer-reviewed works in English-language journals, which were published between 2005 and 2016. The literature was sourced from Science Direct, EBSCO, MEDLINE (Medical Literature Analysis and Retrieval System Online), CINAHL (Cumulative Index of Nursing and Allied Health Literature) and PubMed (US National Library of Medicine).

As part of the process of systematic literature analysis in this paper, a structured search of the academic literature was conducted to find published articles that identified TQM, total quality management, implementation, CSFs, health care and nursing. The keywords used in the search are TQM, total quality management, implementation, critical success factors, health care and nursing.

As presented in Figure 1, a search of Science Direct, MEDLINE, EBSCO, CINAHL and PubMed yielded 2133, 6341, 1867, 7 and 474 articles, respectively. Then, repeated citations, dissertations and case studies were deleted. Via reading of the title and abstract, the remaining articles were narrowed down by relevance. Only peerreviewed academic and practice articles that focus on total quality management, implementation, CSFs health care and nursing were selected. This exercise yielded a

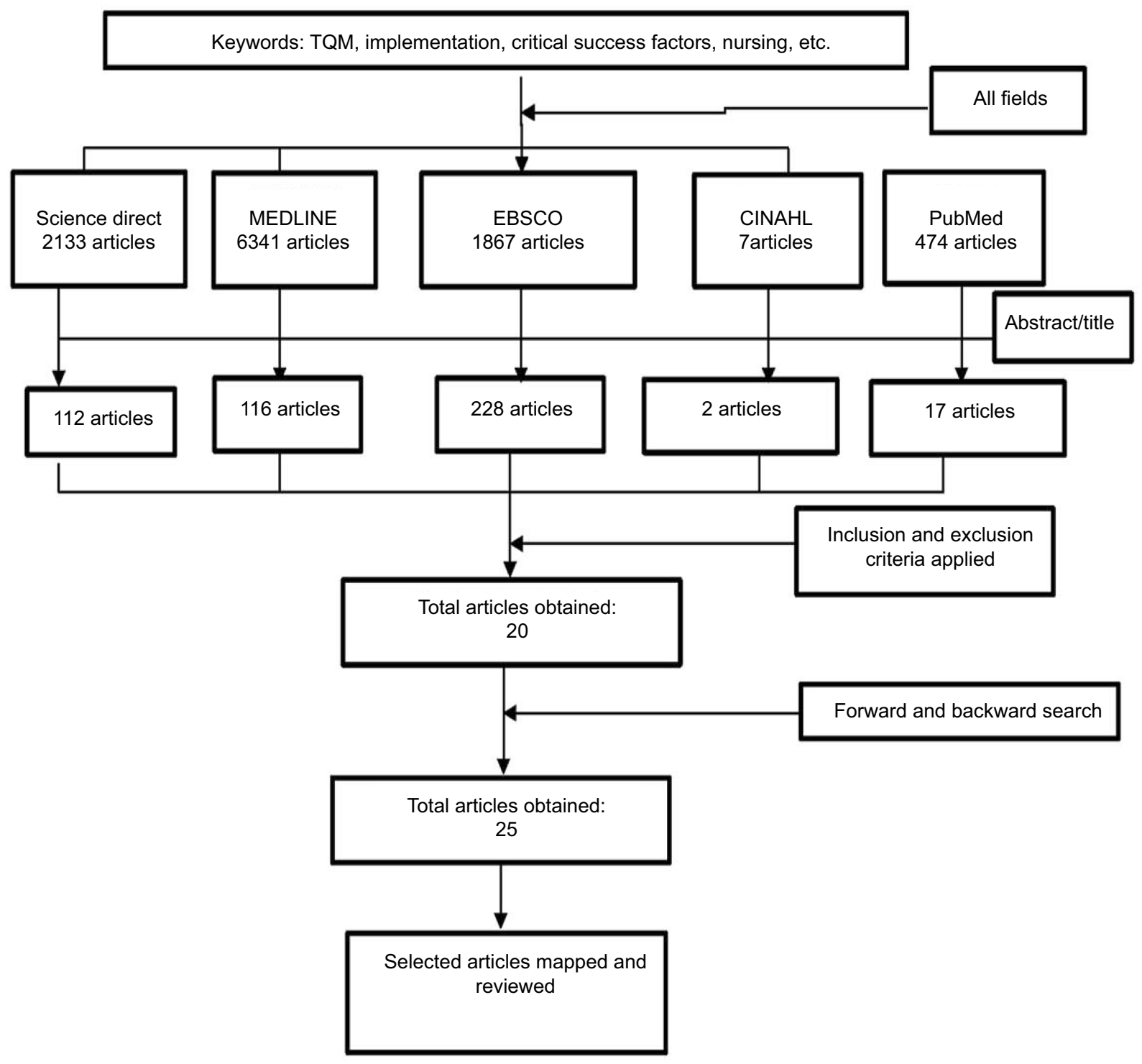

Figure I Consort flow chart of systematic review method. Abbreviation: TQM, total quality management. 
total of 475 articles which were published between 2005 and 2016.

Furthermore, inclusion and exclusion criteria were applied to narrow down the yielded articles. The inclusion criteria involved articles which were written in English language and published between 2005 and 2016, articles that dwell on implementation and critical factors clearly, articles from any geographical location which examined TQM, TQM principles, TQM tools and methods in the context of the health-care sector, and TQM studies that used a quantitative research approach and quasi-experimental research design. The exclusion criteria involved articles which are written in non-English language and published before 2005 or after 2016, studies in which the population and sample were not health-care workers practicing inside hospitals, gray literature or works that are not published in a peer-reviewed journal, dissertations/theses, proceedings, published abstracts, studies with qualitative research methods, and commentary articles written to convey opinion or stimulate research or discussion, with no research component. By employing these inclusion and exclusion criteria, 20 articles were generated. Moreover, to guarantee all-inclusiveness and to widen the scope of the review, a forward and backward search of citations in articles was conducted. This was recognized via the database searches, and 25 articles were finally selected. Thereafter, the 25 generated articles were fully perused.

Likewise, for exhaustive research, the approach adopted in this paper also involved the identification and measurement of predictors (CSFs) of TQM. This was done by identifying the most common or important predictors in the selected 25 works that analyze the existing models and/or scales in other contexts, industries or countries. It also includes recognition of the papers that investigate the influence of TQM implementation and/or the impact of predictors of TQM on performance. Additionally, for a proper review of the selected works, adequate plotting of the development of the line of reasoning, integrating and synthesizing the studies, authors, study design, study population, variables, measures of variables and findings of each selected article were identified and noted down. Figure 1 represents the consort flow chart of the systematic review method.

\section{Findings and discussion}

Altogether, 25 researched articles were eventually reviewed. All of the selected 25 articles are based on empirical evidence, although a possible limitation of this systematic review strategy might be the exclusion of qualitative studies in the research. Based on Table 1, five predictors were identified. These are presented in Table 2.

The researched literature on predictors of successful TQM implementation was found to be from various countries but in the same health sector. While some predictors adopted by a few of the researched studies were identified, the most frequent and core predictors were identified and considered. As depicted in Table 2, education and training, continuous quality improvement, patient focus/satisfaction, top management commitment and teamwork appear to be the core predictors (CSFs) in this review. This finding validates how important these variables are in the successful implementation of TQM in the health-care context.

It is noteworthy that the core predictors (ie, education and training, continuous quality improvement, patient focus/satisfaction, top management commitment and teamwork) identified in this study were among the variables found to be central and frequently used CSFs in the previous systematic-review-based studies. ${ }^{14,21}$ This validates and confirms the findings of the previous studies.

Moreover, it is found that the most adopted research method in TQM in the health-care context is cross-sectional research; $56 \%$ of the reviewed researched articles ${ }^{41-46}$ used a cross-sectional research design, but $32 \%$ of the studies employed a quasi-experimental research approach. This indicates that there is still a need for more research on TQM in the health-care context which will adopt a quasiexperimental research approach, because quasi-experimental research design can be very useful in recognizing general trends from the results, and reduces the difficulty and ethical worries that may be connected with the pre-selection and random assignment of test subjects. On the geographical location aspect, the result of this analysis showed that $28 \%$ of the reviewed studies were conducted in Iran while 20\% of the reviewed studies were conducted in Jordan; $12 \%$ and $8 \%$ of the reviewed studies were conducted in Saudi Arabia and Pakistan, respectively. The other studies, $4 \%$ each, came from India, Namibia, Turkey, the United States, France and Mauritius.

With regards to the influence of predictors on performance in the researched studies, it is found that all of the selected articles ${ }^{47,48,49,50,51}$ that examined the effects of the core predictors (continuous quality improvement, education and training, patient focus/satisfaction, top management commitment and teamwork) of TQM indicate a positive effect of TQM in the health-care sector. 


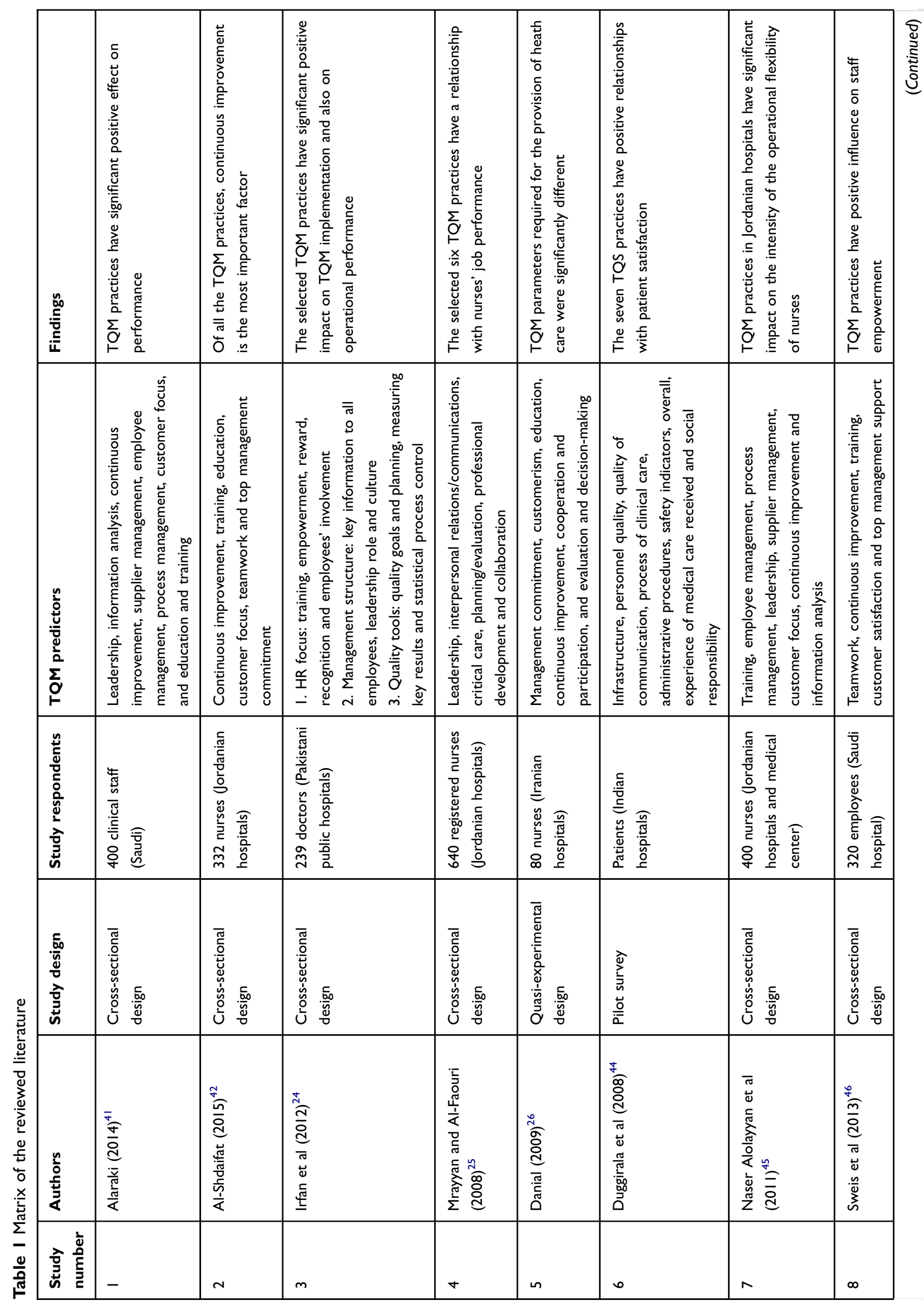




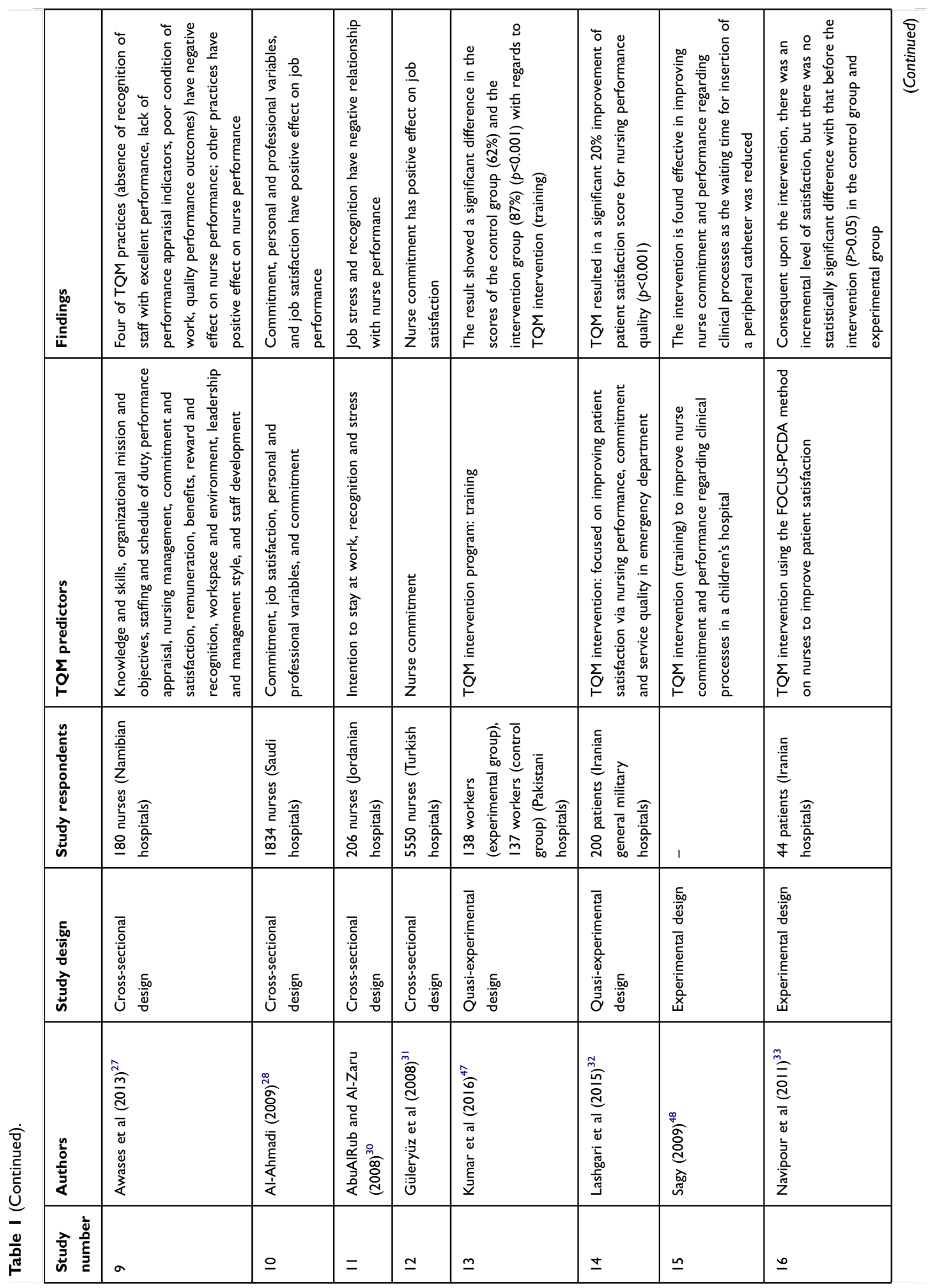




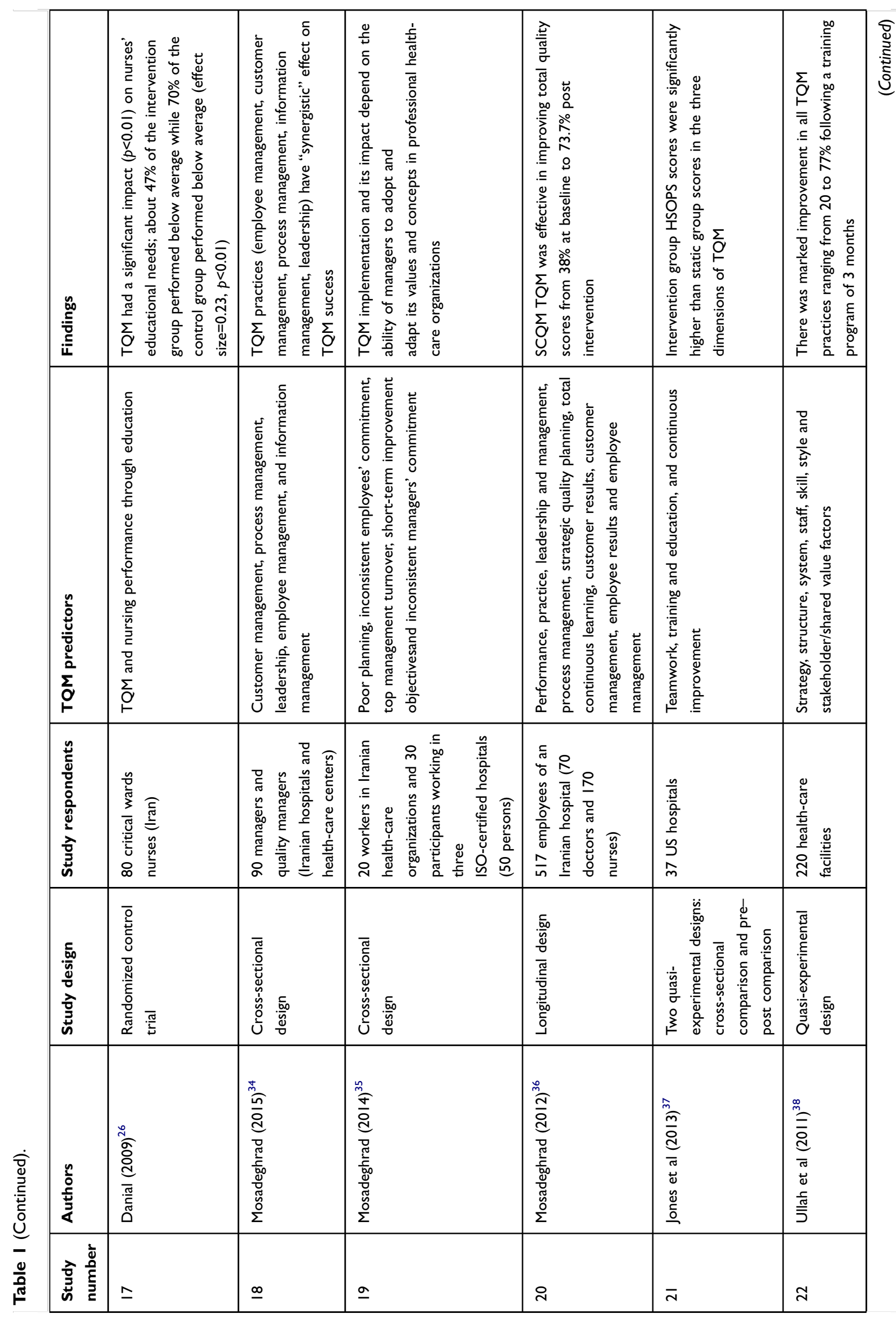




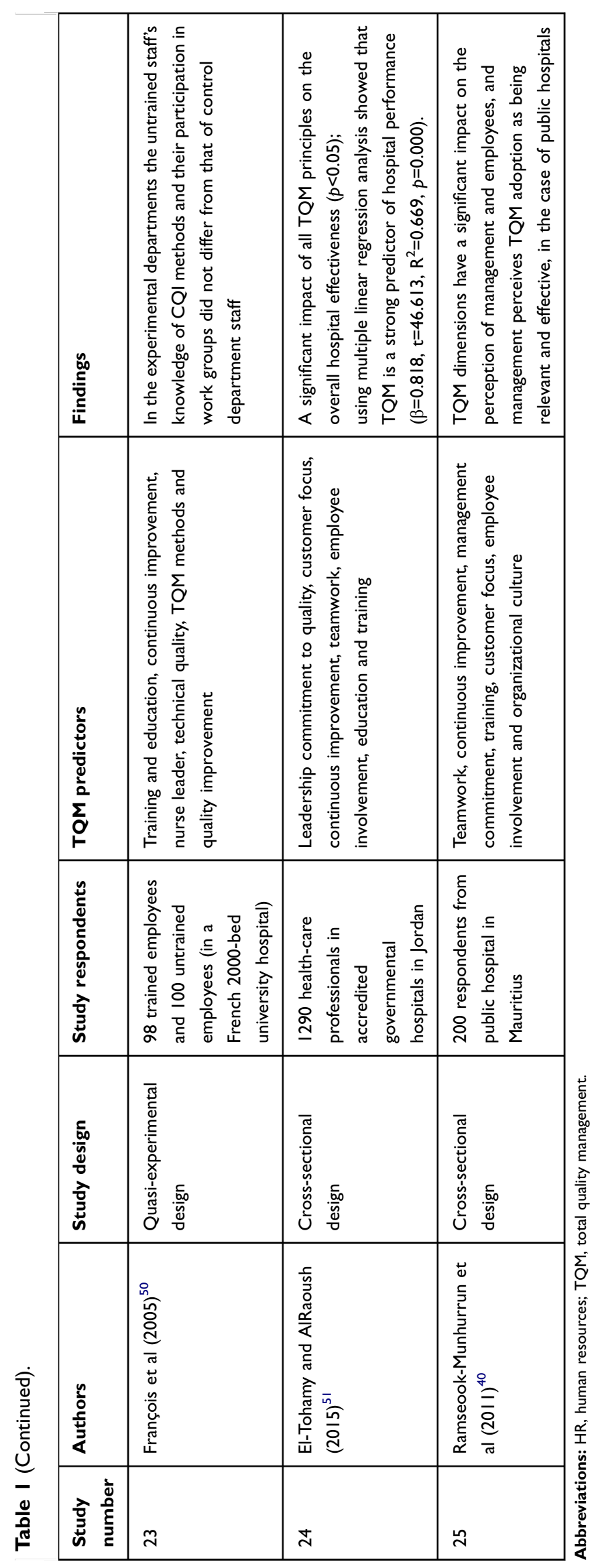


Table 2 TQM predictors in the reviewed studies

\begin{tabular}{|l|l|l|l|}
\hline Study number & TQM predictors in the reviewed studies & $\begin{array}{l}\text { \% of } \\
\text { occurrence }\end{array}$ & $\begin{array}{l}\text { Ranking (based } \\
\text { on frequency) }\end{array}$ \\
\hline $\mathbf{1}$ & & 52 & 1 \\
3 & Education and training & 36 & 2 \\
4 & Continuous quality improvement & 32 & 3 \\
5 & Customer (patient) focus/satisfaction & 32 & 3 \\
6 & Top management commitment & 4 & 4 \\
& Teamwork & 40 & 5 \\
& Others (human resources focus [employee management process, reward, etc]; & & \\
& management structure; quality tools; leadership and management style; & & \\
& interpersonal relations/communications; cooperation and participation; information & & \\
\hline
\end{tabular}

More so, the findings of this review signify that predictors of TQM implementation will result in higher levels of nurse performance. ${ }^{51}$ In addition, the literature and empirical evidence have shown that TQM in an organizational process always results in better performance of the organization. TQM focuses on patient satisfaction, organization problem identification, building and promotion of open decision-making among employees. It embraces a holistic strategy that gives room for every worker to share responsibility for the quality of the work done. It makes use of analytical mechanisms, such as flow and statistical charts and checksheets, to gather information about activities in an organization. ${ }^{52}$ In the medical sector, TQM aims at embedding orientation of quality in all processes and procedures in the delivery of health services. ${ }^{15}$

Nevertheless, this literature survey is not an exhaustive review of the literature on TQM as it solely focused on the effect of TQM. Future research should widen the scope of this paper by including studies conducted in other contexts (eg, education, manufacturing, etc) and studies that use different research methods (eg, longitudinal research method, randomized control trial method). While TQM predictors have increased in number to reach a total of 59 TQM practices, ${ }^{21}$ TQM predictors in the context of health care are few but growing. Investigating the nature of TQM predictors and the methods used in examining them indicates that researchers may have been keen in searching for new predictors instead of trying to cluster them and identify those that are critical for successful TQM implementation. In addition, research on TQM predictors in the health-care sector is scanty, as noted previously.

Practically, given the identified core TQM predictors in this study, it is evident that hospitals' management should consider entrenchment of continuous quality improvement, education and training, patient focus/satisfaction top management commitment and teamwork in the implementation of TQM, which will consequently enhance hospital performance. Given that TQM predictors are many and some of them have been considered core in several specific contexts, industries, dimensions, etc, it is held that stakeholders in different sectors/industries should begin to identify the most vital TQM practices that suit their situations, goals, strategies and expected performances.

\section{Conclusion and recommendations}

As TQM has become an important management approach for advancing performance, this kind of research is of value to researchers and managers. Nevertheless, this study has limitations, including that the databases and search engines adopted for the literature search are not exhaustive. Although a good number of keywords are used, there can be other likely keywords that can be included.

This work has contributed to the enrichment of the relevant literature and made theoretical and methodological contributions. It has provided a foundation on which research on TQM can be built via review of the work done between 2005 and 2016, plotting the development of the line of reasoning, and integration and synthesis of studies from TQM in the health-care context. It has also contributed by evaluating the current state of evidence regarding TQM, indicating inadequacies in the literature and pointing to where further research needs to be done. Thus, it contributes to the present body of knowledge as well as the research on TQM in the health-care context.

This work has also established that the most adopted research method in health-care-based TQM is cross-sectional 
research, followed by quasi-experimental research, and the researched studies were mostly conducted in Asia. The findings of the researched literature indicate a positive effect of TQM in the health-care context, indicating that TQM implementation, which contains the identified core predictors, will result in higher levels of performance. Furthermore, TQM implementation can help health-care professionals to gain more qualified behaviors with total commitment to work toward handling the patients, which in the long run will augment their performance.

The findings of the reviewed studies indicate how it would be useful for stakeholders in the health sectors to introduce and implement TQM in the hospitals and clinics, as this would enhance the performance of the health workers and consequently improve organizational performance. Given the limitations of this work, it is sufficed to suggest that future research should widen the scope of this paper by including studies conducted in other contexts and studies that use different research methods, and it should also develop a comprehensive TQM taxonomy to explain how and why TQM practices coalesce within systems that facilitate higher performance.

\section{Disclosure}

The authors report no conflicts of interest in this work.

\section{References}

1. Bonechi L, Carmignani G, Mirandola R. La Gestione Della Qualità Nelle Organizzazioni-dalla Conformità All'eccellenza Gestionale. Edizioni Plus srl; 2004.

2. Vituri DW, Évora YDM. Total Quality Management and hospital nursing: an integrative literature review. Rev Bras Enferm. 2015;68 (5):945-952. doi:10.1590/0034-7167.2015680525i

3. Antunes M, Sfakiotakis E. Effect of high temperature stress on ethylene biosynthesis, respiration and ripening of 'Hayward'kiwifruit. Postharvest Biol Technol. 2000;20(3):251-259. doi:10.1016/S09255214(00)00136-8

4. Adami C, Ofria C, Collier TC. Evolution of biological complexity. Proc Natl Acad Sci. 2000;97(9):4463-4468. doi:10.1073/pnas.97.9.4463

5. Padilha KG. Iatrogenic occurrences and the quality focus. Rev Lat Am Enfermagem. 2001;9(5):91-96. doi:10.1590/s0104-11692001000500014

6. Haddad M, Évora YDM. Qualidade da assistência de enfermagem: a opinião do paciente internado em hospital universitário público. Ciênc Cuid Saúde. 2008;7:45-52. doi:10.4025/cienccuidsaude.v7i0.6559

7. Wright TA, Bonett DG. The moderating effects of employee tenure on the relation between organizational commitment and job performance: a meta-analysis. J Appl Psychol. 2002;87(6):1183. doi:10.1037/00219010.87.6.1183

8. Aiken LH, Sermeus W, Van Den Heede K, et al. Patient safety, satisfaction, and quality of hospital care: cross sectional surveys of nurses and patients in 12 countries in Europe and the United States. BMJ. 2012;344:e1717. doi:10.1136/bmj.e1717

9. Chang C-S, Chen S-Y, Lan Y-T. Service quality, trust, and patient satisfaction in interpersonal-based medical service encounters. $B M C$ Health Serv Res. 2013;13(1):22. doi:10.1186/1472-6963-13-438
10. McClellan M, Rivlin A. Improving Health while Reducing Cost Growth: What is Possible. Engelberg Center for Health Care Reform at Brookings. 2014.

11. World Health Organization. The World Health Report 2000: Health Systems: Improving Performance. World Health Organization; 2000.

12. Cummings TG, Worley CG. Organization Development and Change. Cengage learning; 2014.

13. Srima S, Wannapiroon P, Nilsook PJP-S, Sciences B. Design of total quality management information system (TQMIS) for model school on best practice. 2015;174:2160-2165.

14. Hietschold N, Reinhardt R, Gurtner S. Measuring critical success factors of TQM implementation successfully-a systematic literature review. Int $J$ Prod Res. 2014;52(21):6254-6272. doi:10.1080/00207543.2014.918288

15. MoHSW T. Implementation Guidelines for 5S-KAIZEN-TQM Approaches in Tanzania. Dar es Salaam (Tanzania): Ministry of Health and Social Welfare; 2013.

16. Mohammad Mosadegh Rad A. The impact of organizational culture on the successful implementation of total quality management. TQM Magazine. 2006;18(6):606-625. doi:10.1108/09544780610707101

17. Ismail Salaheldin S. Critical success factors for TQM implementation and their impact on performance of SMEs. Int J Prod Perform Manage. 2009;58(3):215-237. doi:10.1108/17410400910938832

18. Kumar S, Ghildayal NS, Shah RN. Examining quality and efficiency of the US healthcare system. Int J Health Care Qual Assur. 2011;24 (5):366-388. doi:10.1108/09526861111139197

19. Zairi M, Alsughayir AA. The adoption of excellence models through cultural and social adaptations: an empirical study of critical success factors and a proposed model. Total Qual Manage Bus Excellence. 2011;22(6):641-654. doi:10.1080/14783363.2011.580654

20. Sadikoglu E, Olcay H. The effects of total quality management practices on performance and the reasons of and the barriers to TQM practices in Turkey. Adv Decis Sci. 2014;2014:1-17. doi: $10.1155 / 2014 / 537605$

21. Aquilani B, Silvestri C, Ruggieri A, Gatti C. A systematic literature review on total quality management critical success factors and the identification of new avenues of research. Tqm J. 2017;29(1):184213. doi:10.1108/TQM-01-2016-0003

22. Aquilani B, Silvestri C, Ioppolo G, Ruggieri A. The challenging transition to bio-economies: Towards a new framework integrating corporate sustainability and value co-creation. J Clean Prod. 2018;172:4001-4009. doi:10.1016/j.jclepro.2017.03.153

23. Tranfield D, Denyer D, Smart P. Towards a methodology for developing evidence-informed management knowledge by means of systematic review. Br J Manage. 2003;14(3):207-222. doi:10.1111/ bjom.2003.14.issue-3

24. Irfan S, Ijaz A, Kee D, Awan M. Improving operational performance of public hospital in Pakistan: A TQM based approach. World Appl Sci J. 2012;19(6):904-913.

25. Mrayyan MT, Al-Faouri I. Predictors of career commitment and job performance of Jordanian nurses. J Nurs Manag. 2008;16(3):246256. doi:10.1111/j.1365-2834.2007.00797.x

26. Danial Z. Effect of Total Quality Management in Determining the Educational Needs of Critical Wards Nurses. 2009.

27. Awases MH, Bezuidenhout MC, Roos JH. Factors affecting the performance of professional nurses in Namibia. Curationis. 2013;36 (1):1-8. doi:10.4102/curationis.v36i1.108

28. Al-Ahmadi H. Factors affecting performance of hospital nurses in Riyadh Region, Saudi Arabia. Int J Health Care Qual Assur. 2009;22 (1):40-54. doi:10.1108/09526860910927943

29. Kim K, Han Y, Kwak Y, Kim J-S. Professional quality of life and clinical competencies among Korean nurses. Asian Nurs Res. 2015;9 (3):200-206. doi:10.1016/j.anr.2015.03.002

30. AbuAIRub RF, AL-ZARU IM. Job stress, recognition, job performance and intention to stay at work among Jordanian hospital nurses. $J$ Nurs Manag. 2008;16(3):227-236. doi:10.1111/j.1365-2834.2007.00810.x 
31. Güleryüz G, Güney S, Aydın EM, Aşan Ö. The mediating effect of job satisfaction between emotional intelligence and organisational commitment of nurses: a questionnaire survey. Int J Nurs Stud. 2008;45(11):1625-1635. doi:10.1016/j.ijnurstu.2008.02.004

32. Lashgari MH, Arefanian S, Mohammadshahi A, Khoshdel AR. Effects of the total quality management implication on patient satisfaction in the Emergency Department of Military Hospitals. J Arch Mil Med. 2015;3(1). doi:10.5812/jamm

33. Navipour H, Nayeri ND, Hooshmand A, Zargar MT. An investigation into the effects of quality improvement method on patients' satisfaction: a semi experimental research in Iran. Acta Med Iran. 2011;49(1):38-43.

34. Mosadeghrad AM. Developing and validating a total quality management model for healthcare organisations. TQM J. 2015;27(5):544564. doi:10.1108/TQM-04-2013-0051

35. Mohammad Mosadeghrad A. Why TQM does not work in Iranian healthcare organisations. Int J Health Care Qual Assur. 2014;27 (4):320-335. doi:10.1108/IJHCQA-11-2012-0110

36. Mosadeghrad AM. Implementing strategic collaborative quality management in healthcare sector. Int J Strat Change Manage. 2012;4(3/ 4):203-228. doi:10.1504/IJSCM.2012.051846

37. Jones KJ, Skinner AM, High R, Reiter-Palmon R. A theory-driven, longitudinal evaluation of the impact of team training on safety culture in 24 hospitals. BMJ Qual Saf. 2013;22(5):394-404. doi:10.1136/bmjqs-2012-000939

38. Ullah JH, Ahmed R, Malik JI, Khan MA. Outcome of 7-S, TQM technique for healthcare waste management. J Coll Physicians Surg Pak. 2011;21(12):731-734. doi:12.2011/JCPSP.731734

39. Padma P, Rajendran C, Sai Lokachari P. Service quality and its impact on customer satisfaction in Indian hospitals: Perspectives of patients and their attendants. Benchmarking. 2010;17(6):807-841. doi: $10.1108 / 14635771011089746$

40. Ramseook-Munhurrun P, Munhurrun V, Panchoo A. Total Quality Management Adoption in a Public Hospital: Evidence from Mauritius. 2011.

41. Alaraki MS. The impact of critical total quality management practices on hospital performance in the ministry of health hospitals in Saudi Arabia. Qual Manage Healthcare. 2014;23(1):59-63. doi:10.1097/QMH.0000000000000018
42. Al-Shdaifat EA. Implementation of total quality management in hospitals. $J$ Taibah Univ Med Sci. 2015;10(4):461-466. doi:10.1016/j.jtumed.2015.05.004

43. Larber M, Savis S. Factors affecting nurses organizational commitment. Obzornik Zdravstvene Nege. 2014;48(4):294-301.

44. Duggirala M, Rajendran C, Anantharaman R. Patient-perceived dimensions of total quality service in healthcare. Benchmarking. 2008;15(5):560-583. doi:10.1108/14635770810903150

45. Naser Alolayyan M, Anuar Mohd Ali K, Idris F. The influence of total quality management (TQM) on operational flexibility in Jordanian hospitals: medical workers' perspectives. Asian J Qual. 2011;12(2):204-222. doi:10.1108/15982681111158751

46. Sweis RJ, Al-Mansour A, Tarawneh M, Al-Dweik G. The impact of total quality management practices on employee empowerment in the healthcare sector in Saudi Arabia: a study of King Khalid Hospital Int J Prod Qual Manage. 2013;12(3):271-286. doi:10.1504/ IJPQM.2013.056149

47. Kumar R, Somrongthong R, Ahmed J. Impact of waste management training intervention on knowledge, attitude and practices of teaching hospital workers in Pakistan. Pak J Med Sci. 2016;32(3):705. doi:10.12669/pjms.323.9903

48. Sagy M. Optimizing patient care processes in a children's hospital using Six Sigma. JCOM. 2009;16:9.

49. Denker AG. Transformational Leadership in Nursing: A Pilot Nurse Leader Development Program. 2014.

50. François P, Vinck D, Labarère J, Reverdy T, Peyrin J-C. Assessment of an intervention to train teaching hospital care providers in quality management. BMJ Qual Saf. 2005;14(4):234-239. doi:10.1136/ qshc.2004.011924

51. El-Tohamy AE-MA, Al Raoush AT. The impact of applying total quality management principles on the overall hospital effectiveness: an empirical study on the HCAC accredited governmental hospitals in Jordan. Eur Sci J. 2015;11(10).

52. Kaluzny AD, McLaughlin CP, Simpson K. Applying total quality management concepts to public health organizations. Public Health Rep. 1992;107(3):257.
Risk Management and Healthcare Policy

\section{Publish your work in this journal}

Risk Management and Healthcare Policy is an international, peerreviewed, open access journal focusing on all aspects of public health, policy, and preventative measures to promote good health and improve morbidity and mortality in the population. The journal welcomes submitted papers covering original research, basic science, clinical \& epidemiological studies, reviews and evaluations, guidelines, expert opinion and commentary, case reports and extended reports. The manuscript management system is completely online and includes a very quick and fair peer-review system, which is all easy to use. Visit http://www.dovepress.com/testimonials.php to read real quotes from published authors. 